\title{
La memoria de los lugares: la toponimia
}

María Dolores Gordón Peral, Universidad de Sevilla

El nombre de lugar, el topónimo, en tanto que nombre propio, no posee significado lingüistico, sino únicamente referente: no significa, denomina; su función es meramente identificativa, de etiqueta, pues individualiza a un lugar frente a los circundantes, y dado que el aspecto significativo ocupa un lugar secundario, aunque cambien o desaparezcan los motivos que dieron lugar a su imposición se mantiene y hereda de generación en generación, se transmite con frecuencia incluso de una civilización a la siguiente, de una capa lingüistica a la que se superpone. A pesar de ello, en su origen, es decir en el momento de su creación por parte de la comunidad hablante, ese mismo nombre era una palabra con un significado perfectamente transparente para los miembros de dicha comunidad. Así, aunque un nombre como, digamos, Chirque (de un paraje del término sevillano de Carmona), al ser mera "etiqueta" que lleva el lugar en cuestión para su identificación, no signifique nada para los hablantes actuales, en el momento en que se impuso - hace dos mil años- era una palabra perfectamente interpretable en cuanto a significado, e incluso era evidente a qué hacía referencia: la palabra latina QUERCUS 'encina' (a la que remonta el topónimo) identificaba un referente destacado del lugar - un árbol llamativo y característico del paraje- y facilitaba así la orientación a los hablantes de la zona.

Si logramos determinar el significado que poseía el léxico en que se basan los nombres de lugar -que perviven muchas veces como meros significantes desprovistos de significado, como reliquias fosilizadas de etapas pasadas de la historia lingüistica de una región-, podemos extraer conclusiones de enorme interés para la reconstrucción de la historia local y regional. Para demostrarlo presentaremos en lo sucesivo numerosos ejemplos, analizados detenidamente en los estudios realizados en el marco del proyecto Diccionario Toponomástico de Andalucía Occidental, en el que llevamos trabajando desde hace veinte años (enumeramos los títulos principales en la bibliografia).

Así, el citado nombre Chirque revela, si sabemos interpretarlo lingüisticamente, qué tipo de vegetación caracterizó al lugar en cuestión en época romana. De modo análogo, podemos afirmar que en la misma época el área donde hoy se localiza el barrio sevillano de Palmete era un palmar (PALMETUM), el del pueblo almeriense de Pulpí una zona poblada de chopos (POPULETUM), el del sevillano de El Coronil una donde abundaba el cornejo (CORNETUM), y el del granadino de Lentejí una caracterizada por la abundancia de lentisco (LENTISCETUM). Otros nombres nos hablan de la difusión en siglos pasados de diversos animales salvajes ( $L a$ Lobera, Las Loberuelas, Los Lobos; La Osera; La Gatera, El Gato: seguramente en referencia al lince; Cantarranas; Valdepegas y Hamapega < Majada de las Pegas 'majada de las urracas': GORDÓN, 1995: 220 y ss.).

A veces los nombres que contienen léxico alusivo a la vegetación permiten reconstruir aspectos de la historia agraria de una región: así, los numerosos topónimos del tipo Viña (La Viña Grande, Las Viñas de la Orden, Viñas de Guaditoca, La Viñuela, El Viñazo, etc.), y también otros afines como La Parra, Los Parrales, El Parroso, El Jaenal (de uva jaenal 'variedad de uva'), especialmente frecuentes en una región antaño célebre por sus vinos como la de Guadalcanal (caldos con renombre literario, pues los menciona el propio Cervantes), nos informan sobre el aprovechamiento de numerosos terrenos para la viticultura antes del declive de esta a consecuencia de la plaga de la filoxera a finales del siglo XIX. También otras actividades humanas han dejado huella en la toponimia. Así el pastoreo (Cordel de las Merinas), la minería (Almadén de la Plata, Los Almadenes; Las Minas; Cerro del Hierro; La Bonanza), el transporte de mercancias (Cordel de los Carboneros, de los Recoveros, Vereda de los Arrieros, de los Contrabandistas o de los Estraperlistas, Las Aguardenteras, etc.). Igualmente nos hablan del aprovechamiento humano de los lugares nombres como La Noria, La Zúa o La Azuda (azuda es variante de azud 'presa para sacar agua de un rio'), La Acequia; Los Pozos de la Nieve (cavidades excavadas en el suelo para conservar alimentos refrigerados con las nieves invernales y en las que se mantenía una baja temperatura constante); Los Silos; Los Hornos, El Hornillo (generalmente hornos de cal).

De extraordinario interés son los nombres que aluden a restos de poblamiento anterior al del momento en que fueron impuestos: así, topónimos del tipo EI Villar o Los Villares, Castilleja y Los Castillejos, Los Burguillos o Las Paredes describen plásticamente lo que se encontraron los repobladores medievales de habla castellana en cada sitio (villar y burguillo significan 'restos ruinosos de una población'; Castilleja / castillejo, las ruinas de un castillo); al mismo grupo pertenecen nombres como Los Mármoles, La Ladrillera, La Plata, Las Monedas, El Tesorillo, igualmente alusivos a vestigios de gran interés para la arqueología moderna. En este ámbito se integran así mismo topónimos como La Sepultura de la Reina, Los Baños de la Reina Mora, La Llave, Las Mazmorras, Cerro del Moro, Hoyo de las Tumbas, Los Huesos, etc., cuya interpretación, basada en amplia documentación tanto lingüistica 
como arqueológica, ofrecemos en nuestro libro (GORDÓN PERAL; RUHSTALLER, 1991).

La antigüedad de no pocos topónimos es de cientos y aun de miles de años. La inmensa mayoría de los nombres actualmente en uso en Andalucia, como no podia ser de otro modo, pertenece al estrato más reciente y todavía vigente: el castellano. No obstante, todas las lenguas habladas antes de la reconquista han dejado su impronta en la toponimia regional, principalmente en la macrotoponimia: así, si una localidad conserva un nombre creado en el estrato árabe -pensemos en Alanis, Algeciras, Benacazón, Benaoján, o en las numerosas Alcalá, Alcolea (pueden encontrarse estudios monográficos en ASÍN PALACIOS, 1944 o RUHSTALLER, 2003)- podemos dar por seguro que se trata de fundaciones de época árabe, o al menos de refundaciones de núcleos anteriores temporalmente deshabitados. Nombres como Marchena, Guillena, Cantillana, Escacena, Mairena, en cambio, fueron creados en época romana, concretamente para designar específicamente a los núcleos habitados desde donde se dirigía la explotación de latifundios (PABÓN, 1953; en el periodo árabe, esas mismas explotaciones se denominarian maŷšar - voz que también ha dejado huella en toponimia: Marchamorón, Macharaviaya-, y, después de la reconquista, cortijo). Igualmente romanos son nombres como El Portil (< PORTELLU 'pequeño puerto'), Quintos, Cuarto, Tercia, Chiste (< SEXTUS) (estos cuatro últimos alusivos a miliarios en calzadas romanas), Pesqueril (< PERSICARIETU 'melocotonar'), Santiche (< SENTICETU 'zarzal'), Cote ([MONTE] ACUTU '[monte] agudo'), aunque a menudo suelen clasificarse como mozárabes, ya que, al sufrir la evolución propia del latín en su transformación en romance, presentan los rasgos fonéticos característicos del dialecto románico autóctono del sur peninsular. Claro que cuanto más antiguos son los nombres más dificil se torna su interpretación, hasta tal punto que en muchos casos a lo sumo podemos lanzar hipótesis más o menos atrevidas, y ello no ya acerca de su significado sino incluso acerca de su adscripción exacta a una capa lingüistica u otra: pensemos en formas tan opacas como Sevilla, Córdoba, Huelva, Carmona, Cádiz, Málaga (generalmente estos antiquísimos nombres corresponden a núcleos de población, aunque algunos incluso se conservan en la microtoponimia: Mulva, Carija, Moncloa, Porcún, donde constituyen valiosas pistas para la prospección arqueológica), etc. Aun así, el mero hecho de remontar a estratos anteriores a la romanización y haberse conservado a lo largo de milenios, a pesar de profundos cambios históricos y lingüisticos, es ya de por sí un dato de enorme interés, pues demuestran no sólo la antigüedad de las fundaciones correspondientes, sino también la continuidad del poblamiento (RUHSTALLER, 1992: 350 y ss.).

Como vemos, la explicación de los nombres de lugar entraña todo tipo de dificultades, y a menudo resulta no sólo dificil sino incluso imposible si no estamos dispuestos a abandonar el terreno de lo científico y objetivo. No cabe duda de que la interpretación toponomástica es primordialmente competencia de los lingüistas, quienes han de recopilar documentación histórica original cuanto más antigua (es decir, más cercana al origen del nombre), mejor - lo mismo que las formas orales actualmente en uso entre la población local. Este material documental ha de ser analizado desde los puntos de vista fonético, morfológico, léxico-semántico y dialectológico, y ello dentro del contexto de toda la toponimia regional. No pocas veces se hace necesaria incluso la visita al lugar denominado por el topónimo con el fin de comprobar el aspecto referencial de la interpretación. Una vez establecida la etimología con garantías lingüísticas, el trabajo realizado por el lingüista podrá ser aprovechado por todo tipo de disciplinas, entre las que destacan la historia local y la arqueología. La utilidad del análisis lingüístico basado en una sólida base documental aun trasciende el interés humanístico o científico: así, constituye el punto de partida para el establecimiento de las formas oficiales de los topónimos, asunto este, el de la normalización de la toponimia, aún pendiente en la comunidad autónoma de Andalucía (al igual que en casi todo el dominio del castellano, a diferencia de lo que ocurre en otras lenguas, como el alemán o el francés, e incluso el catalán y el valenciano, el vasco y el gallego). Con el fin de remediar esta lamentable situación hemos iniciado un proyecto de investigación, el proyecto "PRONORMA: Proyecto de recopilación, análisis y normalización de la toponimia de las áreas meridionales de España", que empieza ya a dar sus frutos.

\section{Bibliografía}

ASÍN PALACIOS, M. (1944) Contribución a la toponimia árabe de España. Madrid: [s.n.], 1944 ([Graf. Versal]), 2. ${ }^{\text {a ed. }}$

BENABENT FERNÁNDEZ DE CÓRDOBA, M.; GARRIDO BORREGO, M. T. (dir.) (1990) Inventario de toponimia andaluza. Sevilla: Consejería de Obras Públicas y Transportes, Centro de Estudios Territoriales y Urbanos, 1990, 8 vol.

GORDÓN PERAL, M. D. (1988) Toponimia de la Sierra Norte de Sevilla. Estudio lexicológico. Sevilla: Universidad de Sevilla, 1988

GORDÓN PERAL, M. D. (1990) Del valor interdisciplinar de la investigación lingüistica: toponimia y arqueología. En Actas del XX Congreso de la Sociedad Española de Lingüística. Madrid: Gredos, t. II, pp. 525-536

GORDÓN PERAL, M. D. (1991a) Lengua e Historia: la contribución de la Lingüistica al conocimiento de las épocas anteriores a la Reconquista. Philologia Hispalensis, VI, 1991, pp. 169-180

GORDÓN PERAL, M. D. (1995) Toponimia sevillana. Ribera, Sierra y Aljarafe. Sevilla: Fundación Luis Cernuda, 1995

GORDÓN PERAL, M. D. (ed.) (2010) Toponimia de España. Estado actual y perspectivas de la investigación. Berlín; New York: De Gruyter, 2010

GORDÓN PERAL, M. D.; RUHSTALLER, S. (1991) Estudio léxico-semántico de los nombres de lugar onubenses. Toponimia y arqueología. Sevilla: Alfar-Universidad, 1991

LLORENTE MALDONADO, A. (1971) Toponimia e historia. Granada: Universidad de Granada, 1971

OLIVER ASÍN, J. (1945) Maŷšar = cortijo. Orígenes y nomenclatura árabe del cortijo sevillano. Al-Andalus, X, 1945, pp. 109-126

PABÓN, J. M. (1950-53) Sobre los nombres de la villa romana en Andalucía. En Estudios dedicados a Menéndez Pidal. Madrid: [S. Aguirre], 1950-53, t. IV, pp. 87-165

RUHSTALLER, S. (1990a) Toponimia de la Campiña de Utrera. Sevilla: Diputación Provincial, D. L. 1990

RUHSTALLER, S. (1990b) Interferencia lingüistica en la Sevilla reconquistada: la traditio nominum. En Actas del XX Congreso de la Sociedad Española de Lingüistica. Madrid: Gredos, 1990, pp. 738-748

RUHSTALLER, S. (1992) Toponimia de la región de Carmona. Berna: Francke, 1992 (Romanica Helvetica; 108)

RUHSTALLER, S. (2003) La toponimia andaluza de origen árabe. En Gran Enciclopedia Andaluza del Siglo XXI. Sevilla: Tartessos, 2003, t. II, pp. 314-318 